\title{
Developmental change in reversal learning of an olfactory discrimination
}

\author{
LAWRENCE A. SAPERSTEIN \\ Duke University, Durham, North Carolina \\ DAVID KUCHARSKI \\ Duke University, Durham, North Carolina \\ and Ohio University, Athens, Ohio \\ MARK E. STANTON \\ Environmental Protection Agency, Research Triangle Park, North Carolina \\ and \\ W. G. HALL \\ Duke University, Durham, North Carolina
}

\begin{abstract}
We examined developmental changes in the reversal of a learned discrimination in an olfactory conditioning paradigm in three experiments. Preweanling rats were exposed to an odor (CS+) paired with footshock and a different odor (CS - ) that was explicitly unpaired with footshock. The rats were then immediately tested for their preference between the CS + and CS-odors. In Experiment 1, animals trained at 12 or 18 days of age showed equivalent conditioned aversions to the CS+. When the significance of the cues was reversed, the younger animals showed rapid reversal learning; that is, their aversion to the original CS + was displaced by an aversion to the original CS - . However, the 18-day-old animals were slower to acquire discrimination reversal. In Experiment 2, a similar pattern of results emerged when animals were given separate preference tests involving the CS + versus a novel odor, or the CS- versus a novel odor. In Experiment 3, intact 18-day-old rats and 18-day-olds with damage to the septum and fornix showed equivalent conditioned aversions to the $\mathrm{CS}+$. In contrast to the intact animals, however, the lesioned rats showed rapid reversal of the discrimination, which resembled that of intact 12-dayolds. Thus, there appears to be a dramatic change in reversal learning of conditioned odor aversions in rats after the second week of postnatal life. These data are discussed with reference to the role of septo-hippocampal maturation in the ontogeny of olfactory learning.
\end{abstract}

The study of the neural basis of learning and memory in developing rats has focused on the septo-hippocampal and olfactory systems. Studies of the role of each of these systems in learning have constituted relatively separate lines of analysis. In the case of the hippocampus, parallels have been drawn between various developmental trends in a wide range of learning and memory tasks that are sensitive to hippocampal damage in adults (Altman, Brunner,

\footnotetext{
This research was supported by National Institute of Child Health and Human Development Grant HD17458 to W. G. Hall, and by National Institute of Mental Health Grant MH09436 to David Kucharski. The research described in this article has been reviewed by the Health Effects Research Laboratory, U.S. Environmental Protection Agency, and has been approved for publication. Approval does not signify that the contents necessarily reflect the views and policies of the Agency, nor does mention of trade names or commercial products constitute endorsement or recommendation for use. David Kucharski, at the beginning of a promising career in psychology, died tragically in an automobile accident on October 24, 1987. Address correspondence to Mark E. Stanton, Neurotoxicology Division (MD-74B), U.S. Environmental Protection Agency, Research Triangle Park, NC 27711.
}

\& Bayer, 1973; Amsel \& Stanton, 1980; Douglas, 1975; Nadel \& Zola-Morgan, 1984). More recently, it has been shown that performance on some of these tasks fails to develop normally in rats subjected to neonatal hippocampal damage (Dyck, Sutherland, \& Buday, 1985; Lobaugh, Bootin, \& Amsel, 1985; Pickens \& Stanton, 1988). With respect to the olfactory system, it has been shown that a single olfactory conditioning trial increases focal 2deoxyglucose uptake within the olfactory bulb of 7-dayold rats (Sullivan \& Leon, 1987). In addition, studies have indicated that Pavlovian conditioning of an odor preference during the first 18 days of life leads to an enhanced glomerular response in the olfactory bulb, which may reflect enhanced survival of external tufted cells (Leon et al., 1987). Odor preferences conditioned by pairing odors with oral milk infusions can be lateralized in the 6-day-old rat by restricting olfactory stimulation to a single naris (Kucharski, Johanson, \& Hall, 1986). This lateralization appears to reflect the absence of a commissural projection from the contralateral olfactory system at this age. At 12 days of age, when the olfactory commissural 
projection is present, lateralized learning disappears in the intact rat pup but it can be reinstated by sectioning the anterior commissure (Kucharski \& Hall, 1988). Further analysis of this phenomenon suggests that the neural changes that underlie this form of olfactory conditioning take place in the anterior olfactory nucleus (AON) or at a site caudal to the AON (Kucharski \& Hall, 1989).

We are thus beginning to see progress in our understanding of how limbic and olfactory system maturation contributes to the development of various forms of learning. This progress invites an integration of what have, so far, been essentially independent lines of inquiry involving these different neural systems. Recently, the role of the limbic system in olfactory conditioning has been studied through reversal learning. There have been reports of rapid reversal of olfactory discriminations in adult animals that have received lesions of the lateral entorhinal cortex (Staubli, Ivy, \& Lynch, 1984). The lateral entorhinal cortex sends olfactory projections that synapse on granule cells of the dentate gyrus. Eichenbaum, Fagan, \& Cohen (1986) have also reported rapid reversal of an olfactory discrimination in animals that received fimbriafornix lesions; the fimbria-fornix carries extensive cholinergic projections to the $\mathrm{CA} 3$ and dentate gyrus areas of the hippocampus. These findings suggest that olfactorydiscrimination reversal could serve as a useful paradigm for studying the interactions between the olfactory and limbic systems in the ontogeny of learning.

To test this idea, we compared reversal learning in 12and 18-day-old rat pups. This age comparison was chosen because of the extensive amount of neural maturation that occurs within the septo-hippocampal system during the second and third weeks of postnatal life (Bayer \& Altman, 1974). For example, differentiated dentate granule cells increase dramatically during this period. There is also a marked increase in limbic levels of choline acetyltransferase and acetylcholine, as well as in choline uptake and density of muscarinic receptors at this time (Coyle \& Yamamura, 1976; Hiley, 1976; Kuhar, Birdsall, Burgen, \& Hulme, 1980; McGeer, Fibiger, \& Wickson, 1971). Hence, because 12-day-old animals lack a mature limbiccholinergic system, they may also show the rapid reversal that is observed in adult animals with damage of the lateral entorhinal cortex or fimbria-fornix. By 18 days of age, however, maturation of the septo-hippocampal projection might yield the poor reversal learning that is characteristic of normal adults.

The present study tested this hypothesis with three experiments. In Experiment 1, differences between 12- and 18-day-old rat pups were found in reversal (but not in acquisition) of a discriminative odor aversion; reversal was found at 12 but not at 18 days of age. In Experiment 2 this effect was replicated, and it was further demonstrated that reversal reflected both acquisition of an aversion to the former CS + as well as a loss of an aversion to the former CS - . In Experiment 3, we found that the failure of 18-day-olds to reverse could be prevented by damaging the septum and fornix. Animals with lesions (but not sham controls) showed the rapid reversal that is characteristic of intact 12-day-olds.

\section{EXPERIMENT 1}

In the first experiment, we examined age differences in reversal of an olfactory discrimination. The Pavlovian discrimination paradigm chosen for these experiments consisted of pairing a CS+ odor with footshock and a CS - odor with a nonshock period. During the reversal phase of the experiment, the significance, or value, of the cues was switched for some of the treatment groups so that the original CS + was not paired with shock and the original CS - was paired with shock. Following training, the animals were given a preference test between the $\mathrm{CS}+$ and CS - odors. This paradigm was adapted from one employed by Kucharski and Spear (1984) and by Markiewicz, Kucharski, and Spear (1986). The Pavlovian nature of this paradigm requires no response of the animal during training; during testing, the animal simply makes a choice of spending time in proximity to one of the two odors. Minimizing the response requirements of the task eliminates many of the interpretive problems often associated with developmental studies (Campbell, 1984). Moreover, such a paradigm is a valid test of early learning, as animals as young as $\mathbf{2}$ days of age can demonstrate an olfactory discrimination in a similar two-choice test (Gregory \& Pfaff, 1973).

The odors that served as conditioning stimuli, the shock intensity used, the number of conditioning trials, and the preference-test apparatus were all chosen on the basis of our previous experiments (referenced above) and pilot studies. Specifically, 12- and 18-day-old rats showed equivalent unconditioned preferences for the odorants employed in these studies, and exhibited no change in footshock sensitivity during the given developmental period (Haroutunian \& Campbell, 1979; Kucharski \& Spear, 1984). The number of conditioning trials was chosen to equate original learning; animals of both ages have shown equivalent acquisition of the original discrimination when tested either immediately or $\mathbf{2 4} \mathrm{h}$ after training (Markiewicz et al., 1986).

In additional control studies, we determined that the magnitude of the conditioned aversion was enhanced for both age groups as the number of conditioning trials was increased from that employed in the present study; reducing the number of conditioning trials reduced the strength of the conditioned aversion by an equivalent degree for both age groups. Thus, the rates of learning were equated for both age groups, and "ceiling" or "floor" effects on learning and retention were unlikely to have influenced the results.

\section{Method}

Subjects. The subjects were 6 litters each of 12-and 18-day-old offspring of Charles River CD-strain rats mated in our laboratory at Duke University (no more than one animal from a litter was placed in a particular treatment group, providing an $n$ of 6 in each group). Pregnant females were housed in individual cages $(45 \times 24 \times 20 \mathrm{~cm})$ 
containing wood-chip bedding (Ab-Sorb-Dri, Garfield, NJ). Water and Purina Lab Chow pellets were available continuously. The colony room was maintained at $21^{\circ}-24^{\circ} \mathrm{C}(40 \%-60 \%$ relative humidity) and was on a 14:10 light:dark cycle. Females were checked daily for births at 5:00 p.m.; pups found at that time were termed 0 days of age. At 2 days of age, litters were culled to 10 pups each, with an equal number of males and females. All subjects were trained and tested during the light phase of the light:dark cycle.

Apparatus and Procedure. The animals were given odorfootshock pairings in a $(26.5 \times 19 \times 12.5 \mathrm{~cm})$ Plexiglas apparatus divided into three compartments of equal size. In one compartment, the animals were exposed to the CS+ odorant (paired with footshock) and in another they were exposed to the CS - odorant (without footshock). The middle section served to slow the diffusion of odors. For half of the litters, the CS + was $3 \mathrm{cc}$ of lemon oil (Humco laboratories) and the CS - was 3 cc of methyl salicylate (Fisher Scientific). The other half of the litters received methyl for the CS + and lemon as the CS - . The odorants were spread evenly on pieces of fur attached to wooden rollers at opposite ends of the apparatus. Footshock (.6 mA DC) was delivered by a Lafayette shock generator. All animals were given four conditioning trials. On each trial, the animal was placed in both the CS+ and $\mathrm{CS}$ - compartments for $20 \mathrm{sec}$ (the order of exposure was determined by a Latin-square design). Placement in the first compartment was followed immediately by placement in the other compartment. The rat was removed from the training apparatus during the $30-\mathrm{sec}$ intertrial interval. The sequence was then repeated. Footshock was administered during seconds 8-10 and 18-20 of each 20-sec CS + exposure.

Reversal trials were introduced for some of the treatment groups $60 \mathrm{sec}$ after initial training. Reversal consisted of the substitution of the original $\mathrm{CS}+$ with the original $\mathrm{CS}-$ and vice versa. Animals received either zero, one, or four reversal trials.

The animals received a single 3-min test of preference for methyl versus lemon $1 \mathrm{~min}$ after the training or reversal phases of the experiment. The testing apparatus for preference was a larger version of the conditioning apparatus, consisting of one section $(55 \times 14 \times 15 \mathrm{~cm})$ and a wire mesh floor. This left the animal free to locomote throughout the entire length of the apparatus during testing. The time spent on the lemon or methyl side was recorded during the 3-min testing period. The criterion for entrance into the lemon or methyl side of the apparatus was that the snout be across the midline and into that half of the apparatus. Animals of all age and treatment groups made a clear choice between the odors, and typically huddled next to one of the two sources of odorants. It is noteworthy that previous studies have revealed that animals learn to avoid a CS + odorant, rather than to prefer a CS - odorant (see Experiment 2; Serwatka \& Spear, 1988). Nonetheless, exposure to the CS - facilitates the aversion acquired to the CS+ (Kucharski, Richter, \& Spear, 1985; Kucharski \& Spear, 1984).

\section{Results and Discussion}

There were no age differences in original learning (zeroreversal condition), but the 12 -day-old pups showed more rapid reversal of the original discrimination than did the 18-day-old pups (Figure 1). Although the strength of the aversion to the original CS + was reduced as a function of the number of reversal trials for the 18-day-old animals, they did not display the strong attenuation and reversal of the aversion that was shown by the 12-day-olds after four reversal trials. This difference was reflected statistically by an ANOVA, which yielded a reliable interaction between age and the number of reversal trials $[F(2,25)=$ $12.48, p<.01]$. Newman-Keuls tests indicated that there were no age differences in preference scores after zero

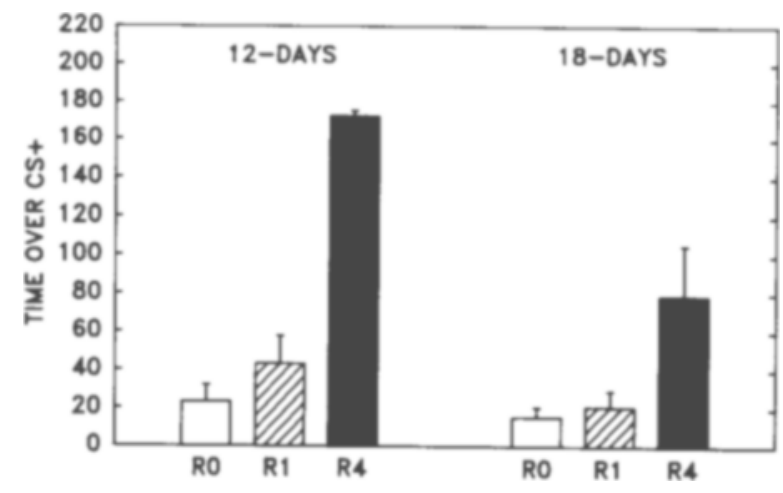

Figure 1. Mean ( \pm SEM) number of seconds spent by subjects in the three treatment groups of Experiment 1 over the CS + during the preference test at 12 and 18 days of age. Scores represent preference for the CS + used in original acquisition training. A score of $90 \mathrm{sec}$ indicates no preference. All groups received acquisition training but differed in the number of reversal trials: $R 0$, no reversal trials; $R 1$, one reversal trial; $R 4$, four reversal trials.

or one reversal trials. However, after four reversal trials, the 12-day-olds showed a greater preference for the original $\mathrm{CS}+$ than did the 18-day-olds $(p<.01)$. For both age groups, preference for the original $\mathrm{CS}+$ increased after four reversal trials $(p<.01)$ relative to the zeroand one-reversal groups, which did not differ $(p>.05)$.

These findings indicate that there were age differences in reversal learning of an olfactory discrimination; younger animals showed more reversal than did older animals. This age difference is consistent with our prediction of impaired reversal based on known maturational changes in the limbic system, and with reports that limbic damage facilitates olfactory-reversal learning.

\section{EXPERIMENT 2}

In the previous experiment, animals were given a preference test for the original CS + and CS - odors. Such a test is sufficient to demonstrate reversal learning; however, the behavioral processes that underlie this effect were not clearly addressed, and several questions remain unanswered. For example, in tests of preference for the $\mathrm{CS}+$ versus the $\mathrm{CS}-$, it cannot be determined whether there is an acquired aversion to the CS + , an acquired preference for the CS-, or both (Serwatka \& Spear, 1988). More relevant to the present data on reversal is the question of whether, for the younger animals, the aversion to the original CS + is still intact after reversal training but is masked by a stronger second aversion acquired to the new $\mathrm{CS}+$ (the previous $\mathrm{CS}-$ ). The younger pups may have actually retained a strong aversion to the original $\mathrm{CS}+$, an aversion that was not expressed in the preferencetest situation because the only alternative to spending time in proximity to the original $\mathrm{CS}+$ was spending time close to the more recent $\mathrm{CS}+$. Conversely, the older animals may have acquired a robust aversion to the new $\mathrm{CS}+$, but one that was not expressed in the preference-test situation. 
In the present experiment, animals were given two preference tests in an attempt to unravel these possibilities. The animals were given a test between the original $\mathrm{CS}+$ and a novel odor, and a test between the original $\mathrm{CS}-$ and the same novel odor. These separate tests permit an assessment of the animals' preference for the CS+ independent of the CS - and vice versa.

\section{Method}

Subjects. The subjects were 12- and 18-day-old rat pups bred, housed, and maintained as described in Experiment 1. Twelve-dayold subjects were divided into groups of 12 drawn from 6 litters, 1 subject per odor condition from each litter; 18-day-old subjects were drawn from 5 litters, 1 subject per odor condition from each litter.

Apparatus and Procedure. The details of the procedure are the same as those described in Experiment 1, with some exceptions. Two of the animals from each litter received lemon as the original $\mathrm{CS}+$ and methyl as the original CS - . The other two received methyl as the original CS + and lemon as the original CS - . One pup from each of these pairs received zero reversal trials and the other pup from each of these pairs received four reversal trials. Littermates' scores were averaged across the two odors within the zero-reversal trial group and the four-reversal trial group (preserving the number of litters as the unit for statistical analysis, $n=5-6$; see Denenberg, 1984) to counterbalance lemon and methyl as either the original CS + or the original CS -. The animals were then given two separate tests (order was counterbalanced between litters) with lemon and cedar odors ( $3 \mathrm{cc}$, Fisher Scientific), and with methyl and cedar. The amount of time spent over lemon or methyl was recorded (as in Experiment 1) during the 3-min preference test.

\section{Results and Discussion}

Reversal training was much more effective in attenuating the original aversion for 12-day-olds than for 18-dayolds (Figure 2). This was demonstrated in a reliable interaction among age, stimulus (CS + vs. CS - ), and the number of reversal trials $[F(1,15)=10.83, p<.01]$.

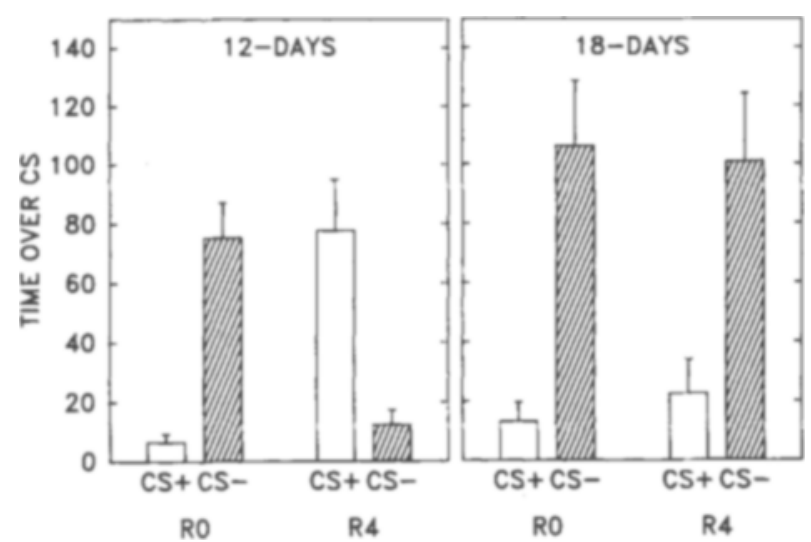

Figure 2. Mean ( \pm SEM) number of seconds spent by subjects in the two treatment groups of Experiment 2 over the CS + or CSduring separate preference tests for each stimulus against a novel odor (cedar). Data for the 12- and 18-day-olds appear in separate panels; data for the two treatment groups appear within each panel. Scores represent preference for the CS + used in original acquisition training. A score of 90 sec indicates no preference. Both groups received acquisition training but differed in the number of reversal trials: R0, no reversal trials; $\mathbf{R 4}$, four reversal trials.
Newman-Keuls tests indicated that there were no age differences $(p>.05)$ in acquisition; for example, there were no age differences in the preference scores for the $\mathrm{CS}+$ or the CS - in the zero-reversal condition. On the other hand, after four reversal trials, 12-day-olds spent more time over the original CS + and less time over the original $\mathrm{CS}-$ (all $p \mathrm{~s}<.01$ ) than did their 18-day-old counterparts. Indeed, the original discrimination was still reliable $(p<.01)$ following reversal at 18 days, whereas it was reliably reversed $(p<.01)$ at 12 days of age.

These findings replicate and extend those of Experiment 1 . They again indicate, with a different testing procedure, that 12-day-olds showed better reversal of an olfactory discrimination than did 18-day-olds. In addition, they indicate that this reversal at 12 days of age consisted both of a loss of an aversion to the original CS + and of an acquisition of an aversion to the original CS - . Conversely, the absence of reversal at 18 days reflects the inability of the reversal procedure to alter the significance of both the CS + and the CS - for these animals. Thus, the age differences in reversal in Experiment 1 probably reflect more than just the establishment of strong aversions to both stimuli, which then are biased in favor of the original $\mathrm{CS}+$ at 18 days and the more recent $\mathrm{CS}+$ at 12 days of age.

\section{EXPERIMENT 3}

We have hypothesized that the enhanced reversal shown by the 12-day-olds may result from limbic system immaturity and, specifically, from the limited amount of synaptic contacts on dentate gyrus granule cells arriving from the septum at this stage of development. Maturation of this input to the hippocampus between 12 and 18 days of age could account for the attenuation of reversal in the older animals (Bayer \& Altman, 1974). In the present experiment, therefore, we sought to test this hypothesis by comparing acquisition and reversal learning of intact 18day-old rats with that of 18-day-olds that received lesions to fiber systems that carry information to the granule cells of the dentate gyrus. As mentioned previously, earlier studies have demonstrated rapid reversal of olfactorydiscrimination learning in adult animals with such lesions (Eichenbaum et al., 1986; Kat, Eichenbaum, \& Cohen, 1983; Staubli et al., 1984). We reasoned that 18-day-old rats with septo-hippocampal damage would show the same rapid reversal learning that is seen in intact 12-day-olds.

\section{Method}

Subjects. A total of 36 subjects were drawn from 6 litters of 18 day-old rats. In each litter, 4 subjects received lesions and 2 received sham surgery. Half of the subjects in the two groups were assigned to the zero-reversal and half to the four-reversal conditions. When 2 subjects from a litter contributed data to a given group, their data were averaged (yielding 1 data point/group/litter). The animals were bred, housed, and maintained as previously described.

Apparatus and Procedure. The details of the procedure were the same as those described for Experiment 1, with some exceptions. Surgery was performed on all subjects in the experimental group prior to behavioral training. The performance of sham- 
operated controls was compared to that of animals with septal/fornix lesions.

Surgery. The rats were anesthetized with Metofane (PitmanMoore). Their heads were shaved and wound areas were aseptically prepared. The animals were hand-held. Anesthesia was maintained from a nose cone as necessary while a midline incision was made over bregma. A 21-gauge needle was used to make a burr hole $2 \mathrm{~mm}$ anterior and $1 \mathrm{~mm}$ lateral to bregma. The side chosen for the hole was evenly distributed among the litters. Transections were made with a 27-gauge needle, rounded at the tip. The needle was inserted into the burr hole at an angle of $65^{\circ}$ from the insertion plane of the skull surface, to a depth of $6 \mathrm{~mm}$. The needle was then passed laterally in each direction to an angle of $20^{\circ}$ from the vertical. In rats that received sham lesions, the 27 -gauge needle was inserted to a depth of $2 \mathrm{~mm}$ and was not passed laterally. Following the lesioning procedure, the animals' wounds were closed with a drop of Vetbond (3M). The rats were allowed to recover in an incubator for $5 \mathrm{~h}$ before training and testing.

Histology. The rats were sacrificed following training and testing. Their brains were removed immediately and frozen. The brains were later sectioned at 20 microns in the sagittal plane, stained with thionin, and mounted. Lesions were characterized with the aid of a standard atlas (Paxinos \& Watson, 1986).

\section{Results and Discussion}

The effects of septal/fornix lesions on olfactorydiscrimination learning and reversal were the same whether lemon or methyl served as the CS+; thus, the data were averaged across this factor. The lesions did not affect acquisition of the discrimination, but dramatically facilitated reversal learning (Figure 3 ). This was demonstrated statistically by a lesion $\times$ groups interaction $[F(1,20)=13.47, p<.01]$. A Newman-Keuls analysis of this interaction revealed no difference between the sham and the lesioned groups following acquisition (zeroreversal group). In both the sham and the lesioned groups, preference for the original CS + was higher following reversal training $(p<.01)$. However, the lesioned animals showed a significantly greater preference $(p<.01)$ for the original CS + than did the sham-lesioned controls.

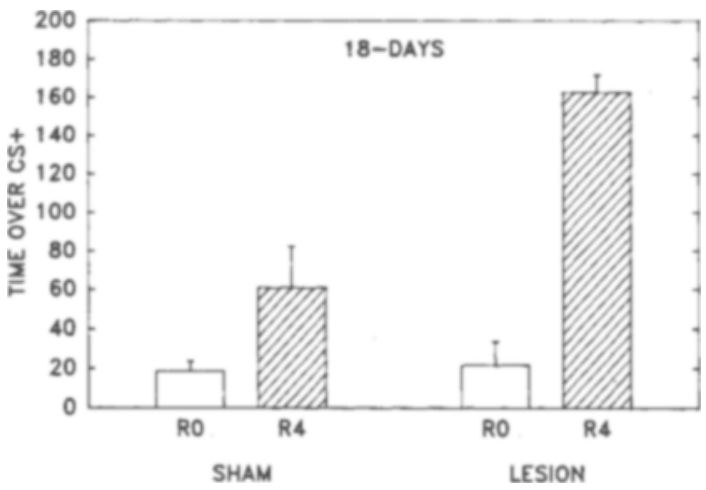

Figure 3. Mean ( \pm SEM) number of seconds spent by subjects in the four treatment groups of Experiment 3 over the $\mathrm{CS}+$ during the preference test at 18 days of age. Scores represent preference for the CS+ used in original acquisition training. A score of $90 \mathrm{sec}$ indicates no preference. All groups received acquisition training but differed in the number of reversal trials: R0, no reversal trials; R4, four reversal trials; SHAM, sham-lesioned controls; LESION, septal/ fornix-lesioned animals.

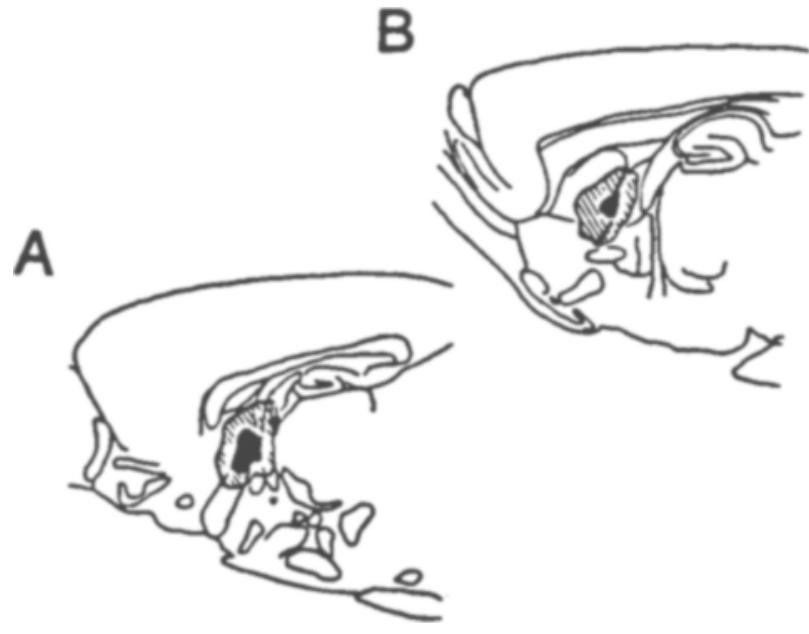

Figure 4. Reconstruction of lesions for subjects that received damage to the septum and fornix in Experiment 3. (A) midsagittal section based on Figure 45 of Paxinos \& Watson (1980); (B) more lateral section based on Figure 47 (damage indicated on this section was symmetrical with respect to the midline). The hatched regions represent damage typical of most animals (12 of 18). The black regions represent damage common to all animals. (Adapted from The rat brain in stereotaxic coontinates, by G. Paxinos and C. Watson, 1986. New York: Academic Press. Copyright 1986 by Academic Press. Reprinted by permission.)

These findings are consistent with the view that the attenuation of reversal learning with increasing age reflects a functional maturation of the septo-hippocampal system. Damage to this system at 18 days of age produced reversal learning that resembled that shown by intact 12-day-olds.

Examination and reconstruction of lesions revealed that all experimental subjects received extensive damage to the lateral septum, medial septum, and fornix (Figure 4). Visual inspection of the reconstructions suggested that the absolute lesion sizes and the distribution of the lesion sizes were approximately equal in both the acquisition and the reversal groups. Three animals were found to have lesions extending ventrally to the anterior commissure, portions of the dorsal hypothalamus, and the most rostral portion of the thalamus. Two subjects were also found to have damage that extended to the dorsal portion of the septum and the corpus callosum. Learning in these subjects was similar to that of other subjects in their group.

\section{GENERAL DISCUSSION}

The results of these experiments demonstrate more rapid reversal of an olfactory discrimination in 12-day-old than in 18-day-old rats. This change in reversal learning occurs during a period of ontogeny that is associated with the maturation of the septo-hippocampal projection. Septal damage produced rapid reversal learning in 18-day-olds, which resembled that of intact 12-day-olds. These findings suggest that maturation of the septo-hippocampal system may account for age differences in olfactory-reversal learning. 
The findings of the present study support those of Eichenbaum et al. (1986) and of Staubli et al. (1984), and demonstrate that facilitation of olfactory-discrimination reversal by limbic system damage is robust across a number of methodological variables. Specifically, Eichenbaum et al. employed an appetitive go/no-go discrimination and lesions of the fornix, whereas Staubli et al. utilized an appetitive two-choice discrimination procedure and lesions of the lateral entorhinal cortex. In both studies, instrumental learning contingencies were in effect and rats were trained on several different discriminations before the effects of the lesions were assessed. In contrast, the present study employed an aversive Pavlovian conditioning procedure, and reversal followed training in only a single discrimination problem. In addition, lesions were to the septal area and the subjects were infant rats rather than adults.

In spite of the fact that the phenomenon appears robust across these variables, it is difficult to find a simple unified explanation for the results of these studies. For example, Staubli et al. (1984) attributed facilitated reversal learning in their study to simple forgetting of the original discrimination. They imposed a 1-h retention interval between the acquisition and reversal phases of their experiment, and presented other evidence that the original discrimination could be forgotten within that amount of time. However, such an explanation does not fit readily with the findings of the present study, in which there was only a 1-min delay between the acquisition and reversal phases. In addition, it has been shown that olfactory discriminations of the kind employed in the present study can be retained for at least $24 \mathrm{~h}$ (Markiewicz et al., 1986). In the Eichenbaum et al. (1986) study, fornix-sectioned and control rats showed comparable retention of the previous discrimination at the outset of reversal learning. As reversal learning progressed, fornix-sectioned rats showed some evidence of a "discrimination learning set" (i.e., they behaved as though reversal was merely another discrimination in the series of problems), whereas control rats behaved as though they had no prior experience with olfactory-discrimination problems. This difference was attributed to interference from a "declarative" memory system in controls that was absent or impaired in fornixsectioned animals. In the present study, facilitated reversal was found in lesioned (and in young) animals after training on a single original discrimination. It is unclear to us what special role a declarative memory system might play in our experimental phenomenon, as the opportunity to develop learning sets does not appear to be necessary for the effect.

Although our data fail to support these other accounts of limbic involvement in olfactory-discrimination reversal, we do not offer an alternative theory that provides a better explanation. In the absence of further experimental analysis of the phenomenon, such an explanation would be overly speculative and premature. What is clear, however, is that damaging inputs to the hippocampal formation enhances olfactory-discrimination reversal, and it does so under a broad range of conditions.
Facilitation of discrimination reversal by hippocampalsystem damage is paradoxical in that impairments in reversal have more commonly been reported (e.g., Berger \& Orr, 1982; Winocur \& Olds, 1978). This paradox has already been discussed at length by Eichenbaum et al. (1986, pp. 1882-1883). We can only add that olfaction may be a sensory modality that has a unique relation to the limbic system (see also Lynch, 1986, p. 58). It is noteworthy that in another study of discrimination reversal in developing rats, 16-day-olds reversed more readily in a T-maze than did 28-day-olds, but only if odor cues were added to the spatial dimension of the task (Wigal, Kucharski, \& Spear, 1984). Thus, rapid reversal learning in immature rat pups and in adults with limbic-system damage may be limited to the olfactory sensory modality. The present series of experiments identifies a narrow age range for the ontogenetic timing of this change in reversal learning.

The present findings support the view that the developing hippocampal system plays a role in the ontogeny of certain forms of learning and memory (Altman et al., 1973; Amsel \& Stanton, 1980; Castro, Paylor, \& Rudy, 1987; Douglas, 1975; Lobaugh et al., 1985; Nadel \& ZolaMorgan, 1984; Schacter \& Moscovitch, 1984). More importantly, the present findings provide an experimental model for examining this role in relation to a type of learning-olfactory Pavlovian conditioning - that is itself becoming well understood at both the behavioral and neural levels in the developing animal (Hall, 1987; Kucharski \& Hall, 1988; Leon et al., 1987). Further application of this model promises to yield an integrated analysis of the interaction between limbic and extralimbic memory systems in the ontogeny of learning.

\section{REFERENCES}

Altman, J., Brunner, R. L., Bayer, S. A. (1973). The hippocampus and behavioral maturation. Behavioral Biology, 8, 557-596.

AMSEL, A., \& STANTON, M. (1980). Ontogeny and phylogeny of paradoxical reward effects. In J. S. Rosenblatt, R. A. Hinde, C. Beer, \& M. Busnel (Eds.), Advances in the study of behavior (pp. 227-274). New York: Academic Press.

Bayer, S. A., Altman, J. (1974). Hippocampal development in the rat: Cytogenesis and morphogenesis examined with autoradiography and low level X-irradiation. Journal of Comparative Neurology, 158, 55-79.

BERGER, T. W., \& ORR, W. B. (1982). Role of the hippocampus in reversal learning of the rabbit nictitating membrane response. In C. D. Woody (Ed.), Conditioning: Representation of involved neural functions (pp. 1-12). New York: Plenum.

CAmpbelL, B. A. (1984). Reflections on the ontogeny of learning and memory. In R. Kail \& N. E. Spear (Eds.), Comparative perspectives on the development of memory (pp. 23-35). Hillsdale, $\mathrm{NJ}$ : Erlbaum.

Castro, C. A., PAylor, R., \& Rudy, J. W. (1987). A developmental analysis of the learning and short-term memory processes mediating performance in conditional-spatial discrimination problems. Psychobiology, 15, 308-316.

COYLE, J. T., \& Yamamura, H. I. (1976). Neurochemical aspects of the ontogenesis of cholinergic neurons in the rat brain. Brain Research, 118, $429-440$.

DENENBERG, V. H. (1984). Some statistical and experimental considerations in the use of the analysis-of-variance procedure. American Journal of Physiology, 246, 403-408. 
Douglas, R. (1975). The development of hippocampal function: Implications for theory and therapy. In R. Isaacson \& K. H. Pribram (Eds.), The hippocumpus (Vol. 1, pp. 327-361). New York: Plenum.

Dyck, R. H., Sutherland, R. J., Buday, M. R. (1985). The ontogeny of mapping and non-mapping spatial strategies following neonatal hippocampal damage in rats. Society for Neuroscience Abstracts, 11, 832.

Eichendaum, H., Fagan, A., Cohen, N. J. (1986). Normal olfactory discrimination learning set and facilitation of reversal learning after medial-temporal damage in rats: Implications for an account of preserved learning abilities in amnesia. Journal of Neuroscience, 6 , 1876-1884.

Gregory, E. H., PFafF, D. W. (1973). Development of olfactoryguided behavior in infant rats. Physiology \& Behavior, 6, 573-576.

HALL, W. G. (1987). Early motivation, reward, learning, and their neural bases: Developmental revelations and simplifications. In N. A. Krasnegor, E. M. Blass, M. A. Hofer, \& W. P. Smotherman (Eds.), Perinatal development: A psychobiological perspective (pp. 169-194). New York: Academic Press.

Haroutunian, V., Campbell, B. A. (1979). Emergence of interoceptive and exteroceptive control of behavior in rats. Science, 205 , 927-929.

HiLeY, C. R. (1976). Ontogenesis of muscarinic receptor sites in the rat brain. British Journal of Pharmacology, 58, 427-428.

Kat, A. G., Eichenbaum, H., \& Cohen, N. J. (1983). Olfactory discrimination and reversal learning in rats with combined hippocampusamygdala lesions. Society for Neuroscience Abstracts, 9, 638.

Kucharski, D., Hall, W. G. (1988). Developmental change in the access to olfactory memories. Behavioral Neuroscience, 102, 340-348.

KuCharski, D., HALL, W. G. (1989). Anterior limb of the anterior commissure is an access rouse to olfactory preference memories. Manuscript in preparation.

KuChaRSKI, D., Johanson, I. B., HaLL, W. G. (1986), Unilateral olfactory conditioning in 6-day-old rat pups. Behavioral \& Neural Biology, 46, 472-490.

Kucharski, D., Richter, N. G., SPEAr, N. E. (1985). Conditioned aversion is promoted by memory of $\mathrm{CS}-$. Animal Learning \& Behavior, 13, 143-151.

Kucharski, D., Spear, N. E. (1984). Conditioning of aversion to an odor paired with peripheral shock in the developing rat. Developmental Psychobiology, 17, 465-479.

Kuhar, M. J., Birosall, N. J., Burgen, A. S., \& Hulme, E. C. (1980). Ontogeny of muscarinic receptors in the rat brain. Brain Research, 184, 375-383.

Leon, M., CoOpersmith, R., Lee, S., Sullivan, R. M., Wilson, D. A., Woo, C. C. (1987). Neural and behavioral plasticity in- duced by early olfactory learning. In N. A. Krasnegor, E. M. Blass. M. A. Hofer, \& W. P. Smotherman (Eds.), Perinatal development: A psychobiological perspective (pp. 145-167). New York: Academic Press.

LobaUGH, N. J., Bootin, M., Amsel, A. (1985). Sparing of patterned alternation but not partial reinforcement effect after infant and adult hippocampal lesions in the rat. Behavioral Neuroscience, 99, 46-59.

LYNCH, G. (1986). Synapses, circuits and the beginnings of memory. Cambridge, MA: MIT Press.

Markiewicz, B., Kucharski, D., Spear, N. E. (1986). Ontogenetic comparison of memory for Pavlovian conditioned aversions to temperature, vibration, odor, or brightness. Developmental Psychobiology, 19, 139-154.

McGeer, F. G., Fibiger, H. C., \& Wickson, V. (1971). Differential development of caudate enzymes in the neonatal rat. Brain Research, 32, 433-440.

Nadel, L., Zola-Morgan, S. (1984). Infantile amnesia: A neurobiological perspective. In $M$. Moscovitch (Ed.), Infant memory (pp. 145 172). New York: Plenum.

PAXINOS, G., WATSON, C. (1986). The rat brain in stereotaxic coordinates. New York: Academic Press.

Pickens, C. V., Stanton, M. E. (1988). Neonatal exposure to the limbic system neurotoxin, trimethyltin, impairs working memory in preweanling rats. Society for Neuroscience Abstracts, 14, 885.

SChacter, D. L., Moscovitch, M. (1984). Infants, amnesics, and dissociable memory systems. In M. Moscovitch (Ed.), Infant memory (pp. 173-216). New York: Plenum.

Serwatka, J., SPear, N. E. (1988). Acquisition and retention of separate elements of a conditioned olfactory discrimination in preweanling rats. Developmental Psychobiology, 21, 145-159.

Staunl, U., Ivy, G., LyNCH, G. (1984). Hippocampal denervation causes rapid forgetting of olfactory information in rats. Proceedings of the National Academy of Science, 81, 5885-5887.

Suluvan, R. M., LEON, M. (1987). One-trial olfactory learning enhances olfactory bulb responses to an appetitive conditioned odor in 7-day-old rats. Developmental Brain Research, 35, 307-311.

Wigal, T., Kucharski, D. . SPEAr, N. E. (1984). Familiar contextual odors promote discrimination learning in preweanling but not in older rats. Developmental Psychobiology, 17, 555-570.

Winocur, G., OLDS, J. (1978). Effects of context manipulation on memory and reversal learning in rats with hippocampal lesions. Journal of Comparative \& Physiological Psychology, 92, 312-321.

(Manuscript received October 28, 1988; revision accepted for publication February 2, 1989.) 